\title{
CO-EVOLUÇÃO DE CULTURA E AMBIENTE NA FORMAÇÃO DO JÊ MERIDIONAL
}

\author{
Rafaela Vieira Nogueira ${ }^{1}$ \\ Pedro Ignácio Schmitz ${ }^{2}$ \\ Jairo Henrique Rogge ${ }^{3}$
}

\section{RESUMO}

O Jê Meridional, grupo nativo do sul do Brasil, segundo os lingüistas, teria sua origem no Planalto Central brasileiro, de onde teria se expandido a partir de cerca de 3.000 anos atrás. Arqueologicamente ele é representado no planalto por 'casas subterrâneas', 'aterros-plataforma' e 'estruturas anelares' e a cerâmica Taquara/Itararé; no litoral, por cemitérios coletivos e grandes casas com sepultamento ao longo das paredes e a mesma cerâmica da tradição Taquara/Itararé. Os dados oriundos de pesquisas mostram evidências de um processo de mudança cultural, que acompanha simultâneas mudanças ambientais. As mudanças culturais mostram consolidação do povoamento em ambas as regiões e as mudanças ambientais, a expansão da Floresta de Araucária no planalto e a Floresta de Restinga na planície litorânea. O objetivo da pesquisa é encontrar a relação entre essas mudanças. A hipótese é que exista uma co-evolução entre elas. Nossa pesquisa baseia-se em evolução cultural, mostrada pela arqueologia e na evolução ambiental, mostrada por estudos palinológicos, buscando relacionar os dois processos. No planalto se percebe a evolução de assentamentos temporários estudados em Rincão dos Albinos, no município de São José do Cerrito, SC, para moradias efetivas com grandes estruturas de terra, estudadas na Boa Parada, no mesmo município, evolução que é coetânea com a expansão e adensamento da Floresta de Araucária por cima dos campos originais. No litoral de Santa Catarina se percebe a evolução de acampamentos temporários com um cemitério central de referência em Içara, para grandes casas com o sepultamento dos mortos em seu interior na ilha de Santa Catarina e no litoral norte, que são paralelos á expansão da Floresta de Restinga e da Mata Atlântica na planície costeira. A partir de pesquisa inicial, já é possível construir um quadro preliminar da inter-relação cronológica entre estas evoluções. A continuação da pesquisa procura compreender melhor e consolidar a evolução de ambos ambientes e destacar as suas relações.

Palavras-chave: Ambiente, Co-evolução, Cultura, Jê Meridional, Planalto catarinense.

\section{INTRODUÇÃO}

\footnotetext{
${ }^{1}$ Instituto Anchietano de Pesquisas/UNISINOS. Bolsista de Iniciação Científica CNPq. Graduanda em Ciências Biológicas (Bacharel) na Unisinos. E-mail: anchietano@unisinos.br.

2 Instituto Anchietano de Pesquisas/UNISINOS. Bolsista de Produtividade Sênior CNPq. E-mail: anchietano@unisinos.br.

3 Instituto Anchietano de Pesquisas/UNISINOS. Bolsista de Produtividade CNPq. E-mail: anchietano@unisinos.br.
} 
Desde 2008, a equipe do Instituto Anchietano de Pesquisas tem realizado pesquisas arqueológicas em São José do Cerrito, SC, encontrando evidências de um processo de mudança cultural dentro da tradição arqueológica Taquara/Itararé, desde cerca de 2.600 até cerca de 300 anos atrás, que estão relacionadas com a formação dos grupos Jê Meridionais (SCHMITZ; ROGGE, 2011; 2013; SCHMITZ et al., 2010; 2013a; 2013-b). Assim como em Taió, SC (SCHMITZ et al., 2009). O objetivo da pesquisa refere-se a quais mecanismos teriam influenciado tais mudanças e a identificar qual a relação entre as mudanças ambientais e as culturais observadas nas áreas de estudo (Figura 1).

Figura 1. Mapa da área, mostrando os sítios em estudo no município e os dois locais de pesquisa intensificada.

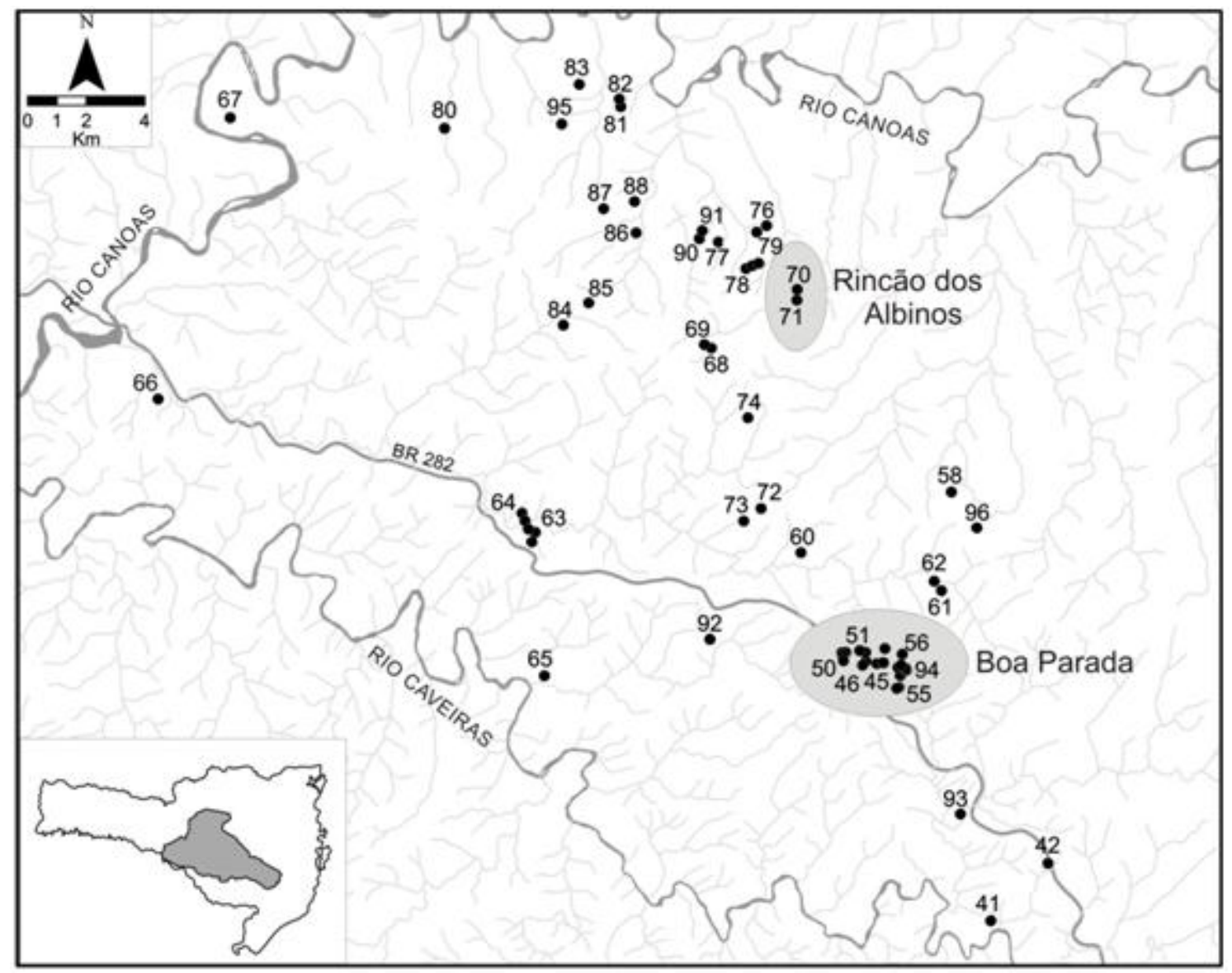

Fonte: Schmitz (Coord.) 2014, p. 29.

A hipótese é de que as mudanças ambientais, especificamente a expansão e consolidação da Floresta com Araucária no Planalto e o crescimento da Floresta de 
Restinga na planície litorânea, teriam exercido um papel fundamental, embora não único, no processo de mudança cultural; portanto de que exista uma co-evolução entre a cultura e o ambiente, entendendo este conceito como a ocorrência de uma transformação evolutiva mútua e simultânea em dois ou mais grupos de diferentes espécies, que apresentem estreitos vínculos ecológicos (NEVES, 1996).

Aspectos dessa co-evolução podem ser observados através do aumento da complexidade material e construtiva percebida nos assentamentos dos grupos Jê Meridionais, que poderia estar em relação com a evolução do ambiente em áreas do Planalto catarinense, bem como no litoral do mesmo estado, envolvendo ainda o manejo de certos elementos da vegetação, decorrente da relação desses grupos com a exploração de recursos.

O Jê Meridional é um grupo lingüístico do sul do Brasil, ligado ao Tronco Macro Jê, representado atualmente pelos índios Kaingang e Xokleng e tem sua origem no Planalto Central brasileiro donde se teria expandido desde cerca de 3.000 anos atrás (WIESEMANN, 1978; URBAN, 1992), devido a um longo período de seca, que teria restringido seus recursos de subsistência, provocando uma pressão demográfica que resultou em dispersão para diferentes áreas, incluindo aí um eixo migratório em direção sul. Esses grupos mantinham estreita relação com o meio em que originalmente viviam e no Planalto e na planície litorânea encontraram um ambiente novo, com oferta de um diferente espectro de recursos, que se encontrava em transformação, de uma paisagem predominantemente aberta, com campos e vegetação herbácea para uma paisagem mais arborizada correspondente à expansão de Floresta Ombrófila Mista a partir de cerca de 1.500 anos AP, e da Floresta de Restinga a partir de aproximadamente 1.340 anos AP.

A evolução da Floresta de Restinga é menos conhecida que a da Floresta com Araucária. Esta teve duas grandes expansões, influenciadas por mudanças climáticas, por volta de 950 e 750 anos AP. Os registros palinológicos mostram, para o período, a diminuição da vegetação campestre e o aumento proporcional da Floresta com Araucária (BEHLING et al., 2004; IRIARTE; BEHLING, 2007; PILLAR et al., 2009).

A expansão florestal pode ter sido favorecida pela maior disponibilidade de água no solo, em locais com menor exposição à radiação solar, expandindo-se a partir das bordas de florestas contínuas (MATTOS, 2011). A pouca disponibilidade hídrica no solo pode ser considerada fator limitante para a expansão florestal, pois a vegetação 
campestre está mais presente em regiões que apresentam uma freqüente restrição de água, especialmente na estação do verão, como ocorre na região Sul do Brasil (PILLAR et al., 2009).

Para germinarem, as sementes das Araucárias necessitam de grande quantidade de luz, que é maior nos campos do que no interior da floresta. Ou seja, além das condições climáticas que favoreciam a expansão da floresta, era necessário um dispersor. Além de diversos animais, o homem pode ter colaborado nessa dispersão.

Estudos arqueológicos relacionam os grupos Jê Meridionais à tradição arqueológica Taquara/Itararé, caracterizada por uma cerâmica típica e pela engenharia de terra para construção de estruturas, como 'casas subterrâneas', 'aterros-plataforma', 'estruturas anelares' e outros montículos.

As casas subterrâneas teriam respondido às necessidades que esses engenheiros de terra tinham, principalmente por conta dos rigores climáticos da região do planalto. Em relação à estrutura dos assentamentos, é possível perceber facilmente que a disposição das casas está estrategicamente voltada para as fontes de água, a menos de 1.000 metros de distância destas, estando suficientemente próximas para que este recurso pudesse ser captado, mas mantendo adequada distância para que as casas não alagassem (NOVASCO, 2013).

Possivelmente, os locais de assentamento não eram escolhidos ao acaso; por estarem compostos de tipos diferentes de vegetação teriam uma variedade maior de recursos vindos de fontes distintas, pois além das sementes da Araucária, teriam acesso às frutas do mato, que, por sua vez, também atraiam animais, e isso reforçaria a alimentação humana.

Conforme Schmitz et al. (2013a) esses grupos, teriam se estabelecido na região para colher pinhão, que estaria disponível no fim do verão e ainda durante o outono, estações em que também amadurecem frutas como Araçá, Guabiroba, Guabiju, Goiabada Serra entre outros.

Além das espécies citadas, sabe-se ainda que se encontram associadas à Floresta Ombrófila Mista outras espécies de Mirtáceas, que teriam potencial alimentício e com isso complementariam a oferta de alimentos, como descrevem Klein (1978), Reitz, Klein e Reis (1983) e também Haverroth (1997) sobre as espécies de frutas silvestres componentes da Floresta com Araucária: a Cereja (Eugênia involucrata), o Guabiju 
(Myrcianthes pungens), o Araçá ( Myrcianthes gigantea), a Uvaia (Eugenia pyriformis), o Guamirim (Myrcia bombycina), a Guabiroba (Campomanesia xanthocarpa), a Jaboticaba (Myrciaria trunciflora) e a Pitanga (Eugenia uniflora).

Dessa forma, é possível perceber que o local escolhido para os assentamentos, oferece uma variedade de fontes nutricionais; entre os fatores que motivam as escolhas humanas, a busca por alimentos é a atividade que exerce maior influência na estrutura e na função que irão adotar nos agrupamentos sociais (MORAN, 1994).

Para o litoral ainda não temos uma compreensão semelhante dos assentamentos e da utilização dos recursos de subsistência.

\section{METODOLOGIA E RESULTADOS}

Foi realizado o estudo sobre a evolução cultural dos grupos Jê Meridionais, baseada na arqueologia e nas informações sobre a evolução do ambiente do planalto sulbrasileiro e da planície litorânea, buscando correlacionar os processos de mudança ambiental e cultural, na área de São José do Cerrito e no litoral de Santa Catarina.

A partir da pesquisa bibliográfica e da pesquisa de campo, foi possível elaborar um panorama preliminar da inter-relação entre os aspectos ambientais e os culturais nas áreas de estudo.

Para a região do Planalto, considera-se que os povoadores iniciais, ainda caçadores e coletores, sem cerâmica e sem construir estruturas superficiais de terra (SCHMITZ et al., 2013a) encontraram um ambiente em transformação de uma paisagem predominantemente de campos com clima frio e seco, para um clima mais quente e úmido, favorecendo a expansão da Floresta com Araucária, de forma ainda pouco expressiva, porém já resultando em mudanças na paisagem, aqui entendida como a junção de diferentes elementos em determinada área, que apresenta uma dinâmica constante de transformação, de fatores naturais e também culturais (BORNAL, 2008 apud NOVASCO, 2013).

Esta transformação pode ser observada através de registros da interação do homem com o ambiente que ele ocupa, ocasionada não somente por motivações biológicas, mas também por escolhas culturais dessas populações (NOVASCO, 2013). 
Os registros palinológicos mostram, por volta de 950 e 750anos AP, duas grandes expansões da Floresta com Araucária, influenciadas por mudanças climáticas (IRIARTE; BEHLING, 2007apud SCHMITZ et al., 2013a).

Concomitantemente, aparecem de forma mais expressiva as construções de terra, superficiais e enterradas e a cerâmica, indicando uma mudança cultural que atinge seu ponto máximo entre os séculos XI e XV, conforme se percebe na evolução de assentamentos temporários, ocorrentes em Rincão dos Albinos, para moradias efetivas com grandes estruturas de terra, observadas na Boa Parada, evolução que é coetânea com a expansão e o adensamento da Floresta de Araucária por cima dos campos originais (SCHMITZ et al., 2013b).

No litoral se percebe a evolução de acampamentos temporários com um cemitério central de referência em Içara, datado entre 1.580 e 1.450 anos AP. (SCHMITZ et al., 1999) para grandes casas com o sepultamento dos mortos em seu interior na ilha de Santa Catarina e litoral norte, datados desde 1.170 até 800 anos AP.(SILVA et al., 1990; SCHMITZ et al., 1993), que são paralelos à expansão da Floresta de Restinga e da Mata Atlântica.

Conforme estudos palinológicos para a Planície litorânea, inicialmente a paisagem era dominada por vegetação herbácea, havendo depois, a partir de 1.340 anos $\mathrm{AP}$, um contínuo aumento nos táxons florestais, que indicam temperatura e umidade mais elevadas (BAUERMANN et al., 2003) (Figura 2).

Figura 2. Gráfico mostrando a evolução da cobertura vegetal no planalto e no litoral e a correspondente presença de assentamentos.

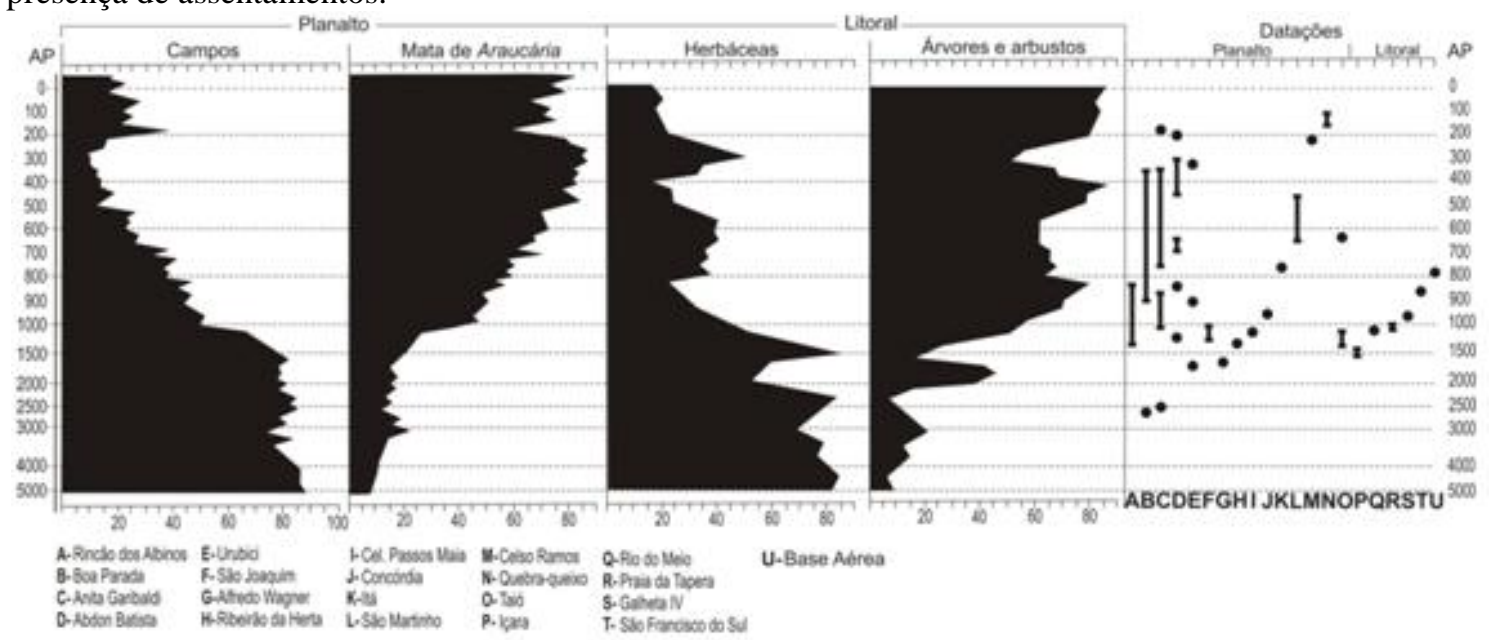

Fonte: Gráfico adaptado de Behling, 2007 apud Schmitz e Rogge, 2013a, p. 93 para o planalto; de Cancelli et al., 2011, p. 4 para o Litoral. Datações segundo Farias; Schmitz, 2013. 
No gráfico (Figura 2) é possível ver, que por volta de 1.500 anos AP, tanto no planalto como no litoral começa a ocorrer uma mudança significativa na vegetação. No planalto, os táxons campestres começam a diminuir e proporcionalmente a Mata de Araucária expande, enquanto no Litoral os táxons herbáceos passam a dar lugar a vegetação arbustiva e arbórea. As datas dos assentamentos acompanham estas modificações e se multiplicam, nos dois ambientes, quando a vegetação arbórea aumenta e se adensa.

Em termos de elementos atuantes, o ambiente em que esses grupos estão inseridos deve ser considerado um dos fatores impulsionadores do processo cultural observado e não somente elemento limitante de seu desenvolvimento (NEVES, 1996).

\section{CONCLUSÃO}

A partir da pesquisa, que é inicial, é possível construir um quadro preliminar da inter-relação cronológica entre a evolução natural e a cultural.

A expansão da Floresta com Araucária e da Floresta de Restinga pode ser vista como um estímulo importante para as mudanças no modo de vida da população local. A expansão natural, junto com o manejo da vegetação arbórea e a prática de queima dos campos pelas populações Jê, aumentariam os recursos naturais aptos para o consumo e assim favoreceriam o desenvolvimento e a expansão da cultura.

De maneira geral, o clima após o final da última Era glacial variou de um ambiente frio e seco para um clima mais quente e úmido ao longo de toda a região, abrangendo assim, a vegetação de diferentes espaços.

A vegetação variou tanto no Planalto como na Planície litorânea, de táxons campestres ou herbáceos para táxons arbustivo/arbóreos. Oferecendo maior variedade de fontes nutricionais permitiu a consolidação dos grupos Jê Meridionais nas duas áreas, consolidação que pode ser identificada no enriquecimento e expansão dos assentamentos tanto numa área como na outra.

Os recursos, especialmente os vegetais, tinham grande importância na vida dessas populações ainda muito próximas e dependentes do meio ambiente e se expressa tanto no aproveitamento intensivo dos elementos naturalmente disponíveis como no seu 
manejo, que implicava conservação, aumento de qualidade e volume, expansão espacial e avaliação moral (HAVERROTH, 1997).

Uma das estratégias de sobrevivência adotadas por populações humanas, segundo Moran (1994), seria a diversificação dos recursos, usada para contornar a possível instabilidade em um determinado ambiente, devido à escassez periódica de alguns elementos. Esta diversificação pode ser natural ou provocada e criada pelo homem.

Além dos instrumentos que os animais têm para sua relação com o ambiente, as populações humanas dispõem, para isso, da cultura (NEVES, 1996), o principal modo de adaptação das populações humanas (MORAN, 1994), que percebe, usa e molda as paisagens.

Durante os milênios de presença no Planalto e na Planície litorânea do Sul do Brasil, as populações Jê utilizaram para sua instalação, fortalecimento e expansão de um ambiente em mudança por modificações no clima e o moldaram para utilidade de sua sociedade, criando paisagens exclusivas, uma para o planalto, outra para o litoral.

A continuação da pesquisa procura compreender melhor e consolidar a evolução de ambos ambientes e destacar as suas relações.

\section{REFERÊNCIAS}

BAUERMANN, S.G. et al. Análises palinológicas da turfeira de Águas Claras, planície costeira do Rio Grande do Sul, Brasil.In: II Congresso sobre Planejamento e Gestão das Zonas Costeiras dos Países de Expressão Portuguesa. IX Congresso da Associação Brasileira de Estudos do Quaternário. II Congresso do Quaternário dos Países de Língua Ibérica- ABEQUA, 2003.

BEHLING, H. et al. Late Quaternary Araucaria forest, grassland (Campos), fire and climate dynamics, studied by high-resolution pollen, charcoal and multivariate analysis of the Cambará do Sul core in southern Brazil. Palaeo, 203:277-297. 2004.

CANCELLI, R.R.; SOUZA, P.A.; DEHNHARDT, B.A. Evolução holocênica da planície costeira sul catarinense (Santa Rosa do Sul, Brasil), através de dados palinológicos e microfaunísticos. In: XIII Congresso da Associação Brasileira de Estudos do Quaternário - ABEQUA, 2011, Búzios, RJ.

FARIAS, D.S.E. de; SCHMITZ, P.I. Linguagem, dispersão e diversidade das populações macro-jê no Brasil Meridional durante a pré-história brasileira. Palhoça: Ed. Unisul. 2013. 
HAVERROTH, M. Kaingang, Um estudo etnobotânico: O uso e a classificação das plantas na área indígena Xapecó (oeste de SC). Dissertação (Mestrado). UFSC, Florianópolis, 1997.

IRIARTE, J.; BEHLING, H. The expansion of Araucária forest in the southern Brazilian highlands during the last 4000 years and its implications of the Taquara/Itararé Tradition. Environment Archaeology, vol. 12, n. 2: 115-127. 2007.

KLEIN, R.M Mapa fitogeográfico do estado de Santa Catarina. In: Reitz, R. (ed.). Flora Ilustrada Catarinense. Itajaí, Herbário Barbosa Rodrigues. 1978.

MATTOS, J.R. O pinheiro brasileiro. Florianópolis: Editora UFSC. 2011.

MORAN, E. F. Adaptabilidade Humana: Uma introdução à antropologia ecológica. São Paulo: Editora da Universidade de São Paulo (Ponta, Vol.10). 1994.

NEVES, W.A. Antropologia ecológica, um olhar materialista sobre as sociedades humanas. São Paulo: Cortez (Questões da nossa época, V59). 1996.

NOVASCO, R.V. As casas subterrâneas e sua paisagem: Cartografando o ambiente. Dissertação (Mestrado) - Curso de História, Programa de pós - graduação em História, Unisinos, São Leopoldo, 2013.

PILLAR, V.D et al. Mosaicos de campos e floresta com Araucária: dilemas para a conservação, p. 273- 283. In: FONSECA, C.R.; SOUZA, A.F.; LEAL ZANCHET, A.M.; DUTRA, T.L.; BACKES, A.; GRANADE, G. (Eds.). Floresta com Araucária: Ecologia, Conservação e Desenvolvimento Sustentável. Ribeirão Preto: Holos Editora. 2009.

REITZ, R.; KLEIN, R.M.; REIS, A. Projeto Madeira do Rio Grande do Sul. Sellowia, Itajaí, v. 34/35, n. 34/35: 5-483. 1983.

SCHMITZ, P.I. (Coord.). As casas subterrâneas de São José do Cerrito. São Leopoldo: Instituto Anchietano de Pesquisas. 2014.

SCHMITZ, P.I.; ROGGE, J.H. Pesquisando a trajetória do Jê Meridional. Pesquisas, Antropologia, 70: 7-33. São Leopoldo: Unisinos. 2013.

SCHMITZ, P.I. et al. Rincão dos Albinos. Um grande sítio Jê Meridional. Pesquisas, Antropologia, 70: 65-131. São Leopoldo: Unisinos. 2013-a.

SCHMITZ, P.I et al. Boa Parada, um lugar de casas subterrâneas, aterros-plataforma e 'danceiro'. Pesquisas, Antropologia, 70: 133-195. São Leopoldo: Unisinos. 2013-b.

SCHMITZ, P.I.; ROGGE, J.H.107 'Casas subterrâneas' no início do povoamento Jê Meridional em Santa Catarina: Rincão dos Albinos. Revista do Museu de Arqueologia e Etnologia, São Paulo, n. 21: 185-204. 2011. 
SCHMITZ, P.I. et al. Casas subterrâneas no planalto de Santa Catarina: São José do Cerrito. Pesquisas, Antropologia, 68: 7-78. São Leolpoldo: Unisinos. 2010.

SCHMITZ, P.I. et al. Taió, no vale do rio Itajaí, SC: O encontro de antigos caçadores com as casas subterrâneas. Pesquisas, Antropologia, 67: 185-320. São Leopoldo: Unisinos. 2009.

SCHMITZ, P.I. et al. Içara: Um jazigo mortuário no litoral de Santa Catarina. Pesquisas, Antropologia, 55. São Leopoldo: Unisinos. 1999.

SCHMITZ, P.I. et al. Escavações arqueológicas do Pe. João Alfredo Rohr, S.J.: O sítio da praia das Laranjeiras II. Uma aldeia da tradição ceramista Itararé. Pesquisas, Antropologia, 49. São Leopoldo: Unisinos. 1993.

SILVA, S.B. da. et al. O sítio arqueológico da Praia da Tapera: um assentamento Itararé e Tupiguarani. Pesquisas, Antropologia, 45. São Leopoldo: Unisinos. 1990.

URBAN, G. A história da cultura brasileira segundo as línguas indígenas. In: Cunha, M.C. da. História dos índios do Brasil. São Paulo: Companhia das Letras, p. 87-102. 1992.

WIESEMAnN, U. Os dialetos da língua Kaingang e Xokleng. Arquivos de Anatomia e Antropologia, vol. III, ano III, Rio de Janeiro. 1978. 